\title{
The limits of a technological fix
}

\author{
Technological innovation is an important contributor to food security and sustainability. But traditional knowledge \\ and behavioural change are vital to solve today's food crisis.
}

F rom bog butter to Golden Rice, technological innovation has had profound impacts on food production and human health over millennia ${ }^{1-3}$. Among technologies expected to aid the production of more and safer food in the future are cultured meat, precision agriculture, drones and artificial intelligence. Yet, technological innovation alone cannot ensure a sustainable food system.

Technology can be broadly defined as the application of knowledge for practical purposes, and may refer to techniques, skills, methods and processes. This definition goes hand-in-hand with the broader concept of innovation, 'an idea, practice, or object that is perceived as new'4. The sphere of impact of a technological innovation is hard to determine and, in truth, depends on the object of interest or the research goal - the eye of the beholder.

The question of what level of impact is socially acceptable or even desirable is certainly not a new one, but becomes ever more pressing in the face of technological developments whose potential to transform nature, individual lives and social systems is unprecedented. The answer has to do with our perception of relative advantage, that is, the degree to which an innovation is perceived as better than the idea it supersedes in terms of socioeconomic gains, social prestige, convenience or satisfaction ${ }^{4}$. These judgements are largely subjective and value-laden, but can be short-sighted in that technology adopters and non-adopters may not be fully aware of the consequences of their choices.

Technologies must be distinguished in terms of the kind and extent of disruption they represent to the status quo. Principles for ethical and socially responsible technological innovation ${ }^{5-8}$ are important to reduce potential risks associated with their uptake. Yet, unquestionably, every technology has pros and cons and most are non-systemic in nature; they tend to solve specific problems and create others down the line. Systemic thinking can only go so far to minimize unintended consequences.

Just as important as acknowledging the limits and risks inherent to technological innovations is understanding that the food crisis is more than a technocratic issue. First and foremost, it has an ethical dimension, manifest in the value attributed to what certain choices forego (for example, biodiversity) and the extent to which people are free to choose. It might be impossible to please everyone or to avoid every unintended consequence of technology deployment, but we should ask ourselves if we are doing everything we can to minimize risks - without losing sight of the value of traditional knowledge or the need for behavioural change.

Knowledge systems embedded in the traditions of regional, indigenous or local communities are not only important sources of information that often end up forgotten or ignored in our current $\mathrm{R} \& \mathrm{D}$ system, but also offer valuable insights in this context. Change in a social system should occur at a rate that is commensurate with the systems' ability to cope with it, and that people can adjust to. Forms of producing, processing and preparing food practiced by traditional communities are embedded in forms of living. Perfecting through experience, they can drive positive transformation without creating detrimental discontinuity, at a pace compatible with communal development and adaptation.

Disruption is welcome when it comes to breaking free from some rigid structures of our current food system. Incremental improvements to food production and consumption will not avoid irreversible trends in terms of climate and biodiversity. Techno-optimistic arguments that ecological disturbance is bound to happen as our species evolves and that we are capable of adapting to new realities may contain some truth, but clash with the persistence of hunger and the aggravation of environmental damage in our society.

The discussion about the role of technological innovation and how much we should rely on it touches on unknown unknowns and the capacity of our species to deal with adversities arising from today's choices. Though it may be illusory to think that a balanced food system can be met despite the world population's imbalance, new challenges require new tools, and technological innovation will be key as we move forward. The point, however, is that thinking of technological innovation as an excuse for inaction or a substitute for the knowledge and experience accumulated over time is unwise. Though technologies might be the utmost expression of human ingenuity and creativity, perhaps our greatest asset is the ability to recognize that a change of course is due.

Published online: 21 April 2021

https://doi.org/10.1038/s43016-021-00275-Z

\section{References}

1. Joardder, M. U. \& Masud, M. H. in Food Preservation in Developing Countries: Challenges and Solutions 57-66 (Springer, 2019).

2. Earwood, C. J. Irish Archaeol. 8, 25-42 (1997).

3. Ye, X., Al-Babili, S., Kloti, A. \& Zhang, J. Science 287, 5451 (2000).

4. Rogers, E. M. Diffusion of Innovations (Simon and Schuster, 2010).

5. Responsible Use of Technology (BSR, World Economic Forum, 2019); http://www3.weforum.org/docs/WEF_Responsible_Use_ of_Technology.pdf

6. Stilgoe, J., Owen, R. \& Macnaghten, P. Res. Policy 42 $1568-1580$ (2013).

7. Van der Burg, S., Bogaardt, M. J. \& Wolfert, S. NJAS-Wagen. J. Life Sci. 90, 100289 (2019).

8. Framework for Responsible Innovation (EPSRC, UKRI, 2021); https://epsrc.ukri.org/index.cfm/research/framework/ 